\title{
Understanding through interactive scaffolding in the Facebook community
}

\begin{abstract}
Thanks to the fast development of various computer-based technologies, as such that, the potential influence that they can have on both academic and personal lives cannot be ignored. This paper aimed to shed more light on the pedagogical values of using web -based technologies such as Facebook on enhancing students' learning through interactive scaffolding. This study was conducted on postgraduate students attending Educational Statistics course. The data collection procedure was based on qualitative responses via Facebook communications. The results of the interviews were indicative of the positive effect, which web-based technologies have on their learning of several statistics topics. This mode of learning, via Facebook, act as interactive scaffolding in strengthening the students' further understanding of statistics topics. In addition, the participants responded that they improve their learning through sharing and discussing different ideas on the various webbased pages. Hence, use of Facebook may act as scaffoldings, which can enhance understanding among learners.
\end{abstract}

Keyword: Interactive learning; Scaffolding; Facebook; Technology 